\title{
A STUDY ON THE BEHAVIOR OF BORON DISTRIBUTION IN LOW CARBON STEEL BY PARTICLE TRACKING AUTORADIOGRAPHY
}

\author{
DONG JUN MUN ${ }^{1}$, EUN JOO SHIN ${ }^{2}$, and YANG MO KOO KN, $^{\text {, }}$ \\ ${ }^{1}$ Graduate Institute of Ferrous Technology, Pohang University of Science and Technology \\ Pohang, South Korea 790-784 \\ ${ }^{2}$ Neutron Science Division, Korea Atomic Energy Research Institute \\ Daejeon, South Korea 305-353 \\ "Corresponding author. E-mail : Koo@postech.ac.kr
}

Received December 21, 2010

The behavior of the non-equilibrium grain boundary segregation of boron in low carbon steel was studied through a particle tracking autoradiography. The behavior of the non-equilibrium grain boundary segregation of boron during continuous cooling was compared with the isothermal kinetics of the non-equilibrium grain boundary segregation of boron at the holding temperature using an effective time method. On the basis of the experiments, the cooling rate dependence of the non-equilibrium segregation of boron was explained using the time dependence of the non-equilibrium segregation of boron in low carbon steel. The experimental observations for the cooling rate dependence of the grain boundary segregation of boron are in good agreement with the time dependence of the grain boundary segregation of boron. The mechanisms of the non-equilibrium segregation of boron during cooling in low carbon steel are also discussed.

KEYWORDS : Boron, Particle Tracking Autoradiography, Non-equilibrium Grain Boundary Segregation, Effective Time Method

\section{INTRODUCTION}

It has been well established that the addition of a small amount of boron remarkably increases the hardenability of low alloy steels $[1,2]$. This beneficial effect is attributed to the grain boundary segregation of boron, which retards the transformation of austenite to ferrite by reducing the grain boundary energy. In order to maximize the effect of boron in steels, it is necessary to control the segregation and precipitation, which usually depends on the alloying elements $(\mathrm{N}, \mathrm{Ti}, \mathrm{Mo})$ and various processing parameters such as austenizing temperatures, cooling rates, heat treating temperatures, and so on.

The grain boundary segregation of boron in steel is known to occur through two types of mechanisms: equilibrium and non-equilibrium segregation [3]. Equilibrium grain boundary segregation occurs by the movement of solute atoms from the matrix to loosely packed sites such as grain boundaries and free surfaces. The driving force for the equilibrium segregation is a reduction of the grain boundary free energy. Nonequilibrium grain boundary segregation (NGS) occurs during cooling from high temperatures by the mobile vacancy-solute complexes diffusing down vacancy gradients towards vacancy sinks. The mechanism of the NGS depends on the formation of sufficient quantities of vacancy-solute complexes. It has been widely accepted that the NGS of boron in steel is the dominating process [4].

The present study is an investigation of the behavior of the NGS of boron during cooling in low carbon steel. The cooling rate dependence of the NGS of boron was examined through the time dependence of the NGS of boron in low carbon steel. A comparison between the cooling rate dependence and the time dependence of the NGS of boron will lead to a better understanding of the NGS mechanisms.

\section{EXPERIMENTAL PROCEDURE}

The chemical composition of the low carbon steel used in this study is shown in Table 1 . The steel was prepared through laboratory vacuum induction melting and hotrolled into $30 \mathrm{~mm}$ thick plates followed by ambient air 
cooling to room temperature. Cylindrical samples of 4 $\mathrm{mm}$ diameter and $12 \mathrm{~mm}$ length were machined from the plates with the longitudinal direction parallel to the rolling direction. Heat treatment was performed using a hot deformation simulator. In the continuous cooling treatment, the sample was heated from room temperature to $1200{ }^{\circ} \mathrm{C}$ at a rate of $10{ }^{\circ} \mathrm{C} / \mathrm{s}$, austenized for $300 \mathrm{~s}$, and then cooled to room temperature at a cooling rate ranging from 1 to $100{ }^{\circ} \mathrm{C} / \mathrm{s}$. In the isothermal holding treatment, the sample was heated from room temperature to $1200{ }^{\circ} \mathrm{C}$ at a rate of $10^{\circ} \mathrm{C} / \mathrm{s}$, austenized for $300 \mathrm{~s}$, and then quenched to $900{ }^{\circ} \mathrm{C}$ at a cooling rate of $50{ }^{\circ} \mathrm{C} / \mathrm{s}$. After holding for times between 0 and $1000 \mathrm{~s}$ at $900{ }^{\circ} \mathrm{C}$, the sample was quenched to room temperature by water spraying. In order to minimize oxidation, all tests were conducted in an argon atmosphere. The heat treatments are described schematically in Fig. 1.

The distribution of the boron in the sample was determined using a particle tracking autoradiography (PTA) method. The PTA technique is a powerful tool for the study of boron distribution in steels. This technique is based on the detection of the alpha-particles emitted from the thermal neutron ${ }^{10} \mathrm{~B}(\mathrm{n}, \alpha){ }^{7} \mathrm{Li}$ reaction in a solid state track detector. The detecting boron sensitivity of the PTA method is $1 \mathrm{ppm}$ and the spatial resolution is $2 \mathrm{ym}$. Cellulose nitrate film was used as detecting foils. The thermal neutron flux was $1.0 \times 10^{13} \mathrm{n} / \mathrm{cm}^{2} \cdot \mathrm{s}$, and the irradiation time was $6 \mathrm{hrs}$. After irradiation, films were etched in an aqueous solution of $2.2 \mathrm{~N} \mathrm{NaOH}$ at $55^{\circ} \mathrm{C}$ for $9 \mathrm{~min}$. The etched films were examined using the optical microscope.

\section{RESULTS AND DISCUSSION}

\subsection{Cooling Rate Dependence of Boron Distribution in Low Carbon Steel}

It is known that the grain boundary segregation of boron in steel occurs during cooling from high temperatures [5, 6]. This is generally known as non-equilibrium segregation phenomena. The non-equilibrium segregation is caused by the diffusion of vacancy-boron complexes to the grain boundaries and depends strongly on the cooling rate. The maximum grain boundary segregation occurs at a certain intermediate cooling rate [5], which is defined as the critical cooling rate [7]. If the cooling rate is faster than the critical cooling rate, there is insufficient time to reach the maximum grain boundary segregation during cooling, and if the cooling rate is slower than the critical cooling rate, the desegregation of boron from the grain boundaries to the matrix occurs resulting in the degree of the grain boundary segregation decreasing gradually. The effect of the cooling rate on the boron distribution is illustrated in Fig. 2. The amount of grain boundary segregation of boron increased

Table 1. Chemical Composition of the Low Carbon Steel (Weight Percent)

\begin{tabular}{c|c|c|c|c|c|c|c|c|c}
\hline $\mathrm{Fe}$ & $\mathrm{C}$ & $\mathrm{Si}$ & $\mathrm{Mn}$ & $\mathrm{Cr}$ & $\mathrm{Ni}$ & $\mathrm{Mo}$ & $\mathrm{Ti}$ & $\mathrm{N}$ & $\mathrm{B}$ \\
\hline ba1 & 0.07 & 0.51 & 2.00 & 0.3 & 0.2 & 0.2 & 0.02 & 0.0044 & 0.0022 \\
\hline
\end{tabular}

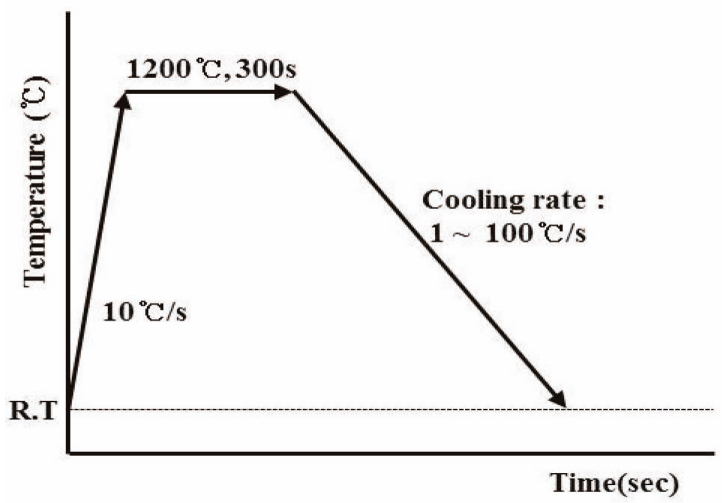

Treatment (A)

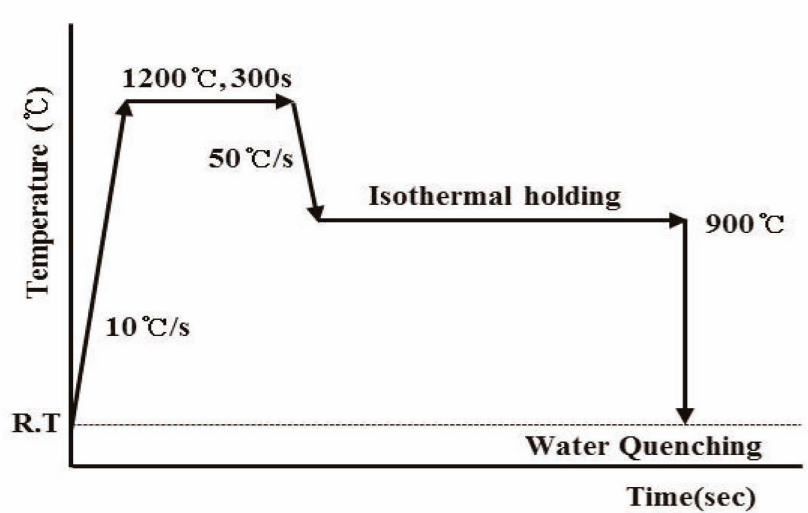

Treatment (B)

Fig. 1. Schematic Diagram of the Procedure of Heat Treatment: (A) Continuous Cooling Treatment and (B) Isothermal Holding Treatment. 
with decreasing cooling rate to approximately $10{ }^{\circ} \mathrm{C} / \mathrm{s}$. The degree of segregation is highest at the intermediate cooling rate of approximately $10 \sim 20{ }^{\circ} \mathrm{C} / \mathrm{s}$ and then decreases with the decreasing cooling rate. The boron distribution changed at a slow cooling rate of $1{ }^{\circ} \mathrm{C} / \mathrm{s}$; the grain boundary precipitates were detected at this slow cooling rate.

From the above experimental results, it can be concluded that the critical cooling rate of the sample in
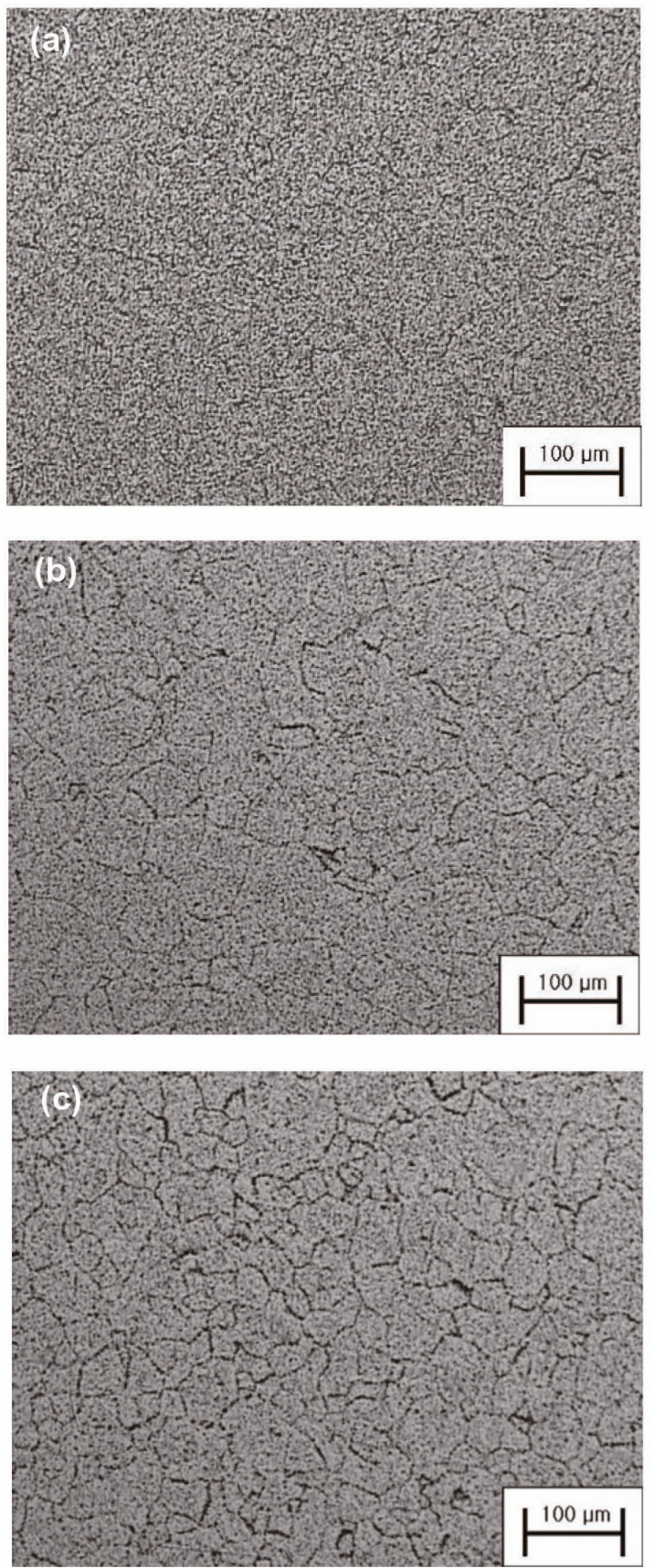

this study is between approximately 10 and $20^{\circ} \mathrm{C} / \mathrm{s}$. Karsson and Norden [5] showed that the degree of nonequilibrium segregation of boron after cooling from $1075^{\circ} \mathrm{C}$ increases with a decreasing cooling rate from $530^{\circ} \mathrm{C} / \mathrm{s}$ to $27^{\circ} \mathrm{C} / \mathrm{s}$, then decreases with a decreasing cooling rate to $0.25^{\circ} \mathrm{C} / \mathrm{s}$, which is consistent with the segregation behavior of boron observed in this study. They suggested that the critical cooling rate to provide the maximum grain boundary segregation of boron in steel is approximately $13{ }^{\circ} \mathrm{C} / \mathrm{s}$ after cooling from $12500^{\circ} \mathrm{C}$, which also agrees well with the experimental results presented here.

\subsection{Time Dependence of Boron Distribution in Low Carbon Steel}

According to the isothermal kinetics of the NGS of boron, the processes of non-equilibrium segregation can be divided into segregation and desegregation processes [8]. When the sample is cooled quickly from a higher temperature to a lower temperature and then held at this lower temperature, vacancy-boron complexes begin to diffuse towards the grain boundaries. The maximum grain boundary segregation of boron at this lower
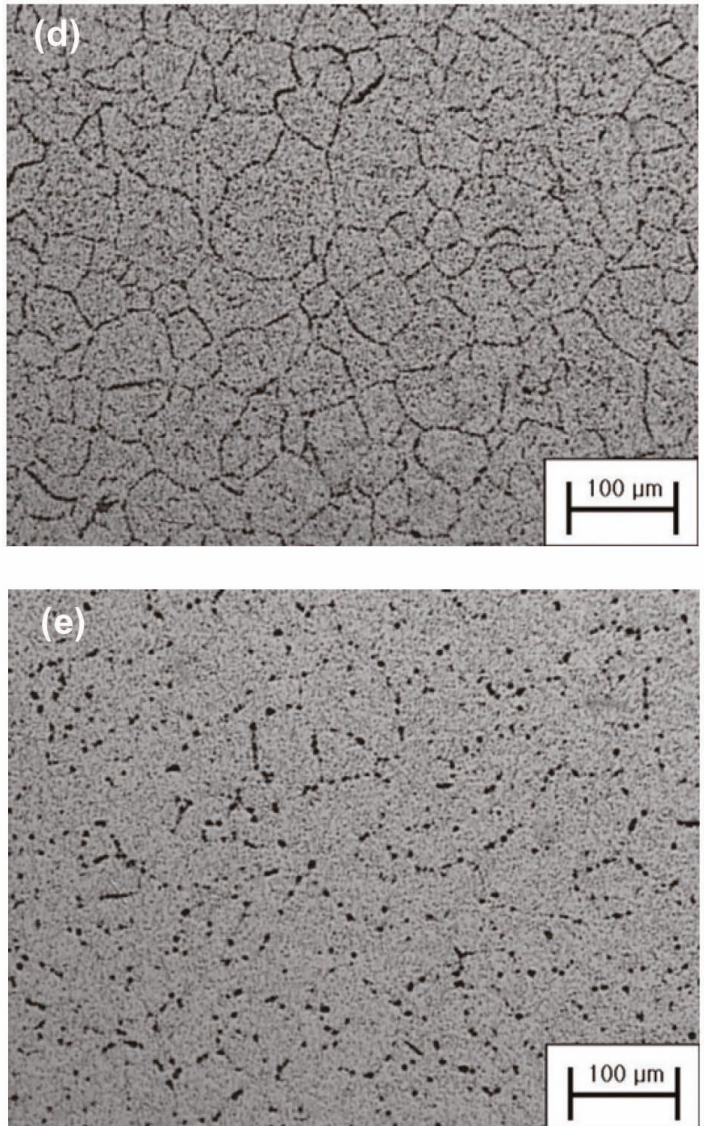

Fig. 2. Boron Distribution after Cooling from $1200{ }^{\circ} \mathrm{C}$ : (a) $100{ }^{\circ} \mathrm{C} / \mathrm{s}$, (b) $40{ }^{\circ} \mathrm{C} / \mathrm{s}$, (c) $20^{\circ} \mathrm{C} / \mathrm{s}$, (d) $10^{\circ} \mathrm{C} / \mathrm{s}$, and (e) $1{ }^{\circ} \mathrm{C} / \mathrm{s}$. 
holding temperature occurs at a certain time. This is generally known as the critical time [7]. If the holding time at this lower temperature is shorter than the critical time, the segregation of the vacancy-boron complexes from the matrix to the grain boundaries will be dominant. If the holding time is longer than the critical time, desegregation of boron from the grain boundaries to the matrix will be dominant. Therefore, the critical time is equal to the transition time from segregation to desegregation during the isothermal holding at this lower temperature. This is an original characteristic aspect of the NGS. Figure 3 shows the behavior of the boron distribution with an increasing holding time at $900{ }^{\circ} \mathrm{C}$ after quenching from $1200{ }^{\circ} \mathrm{C}$. The degree of segregation
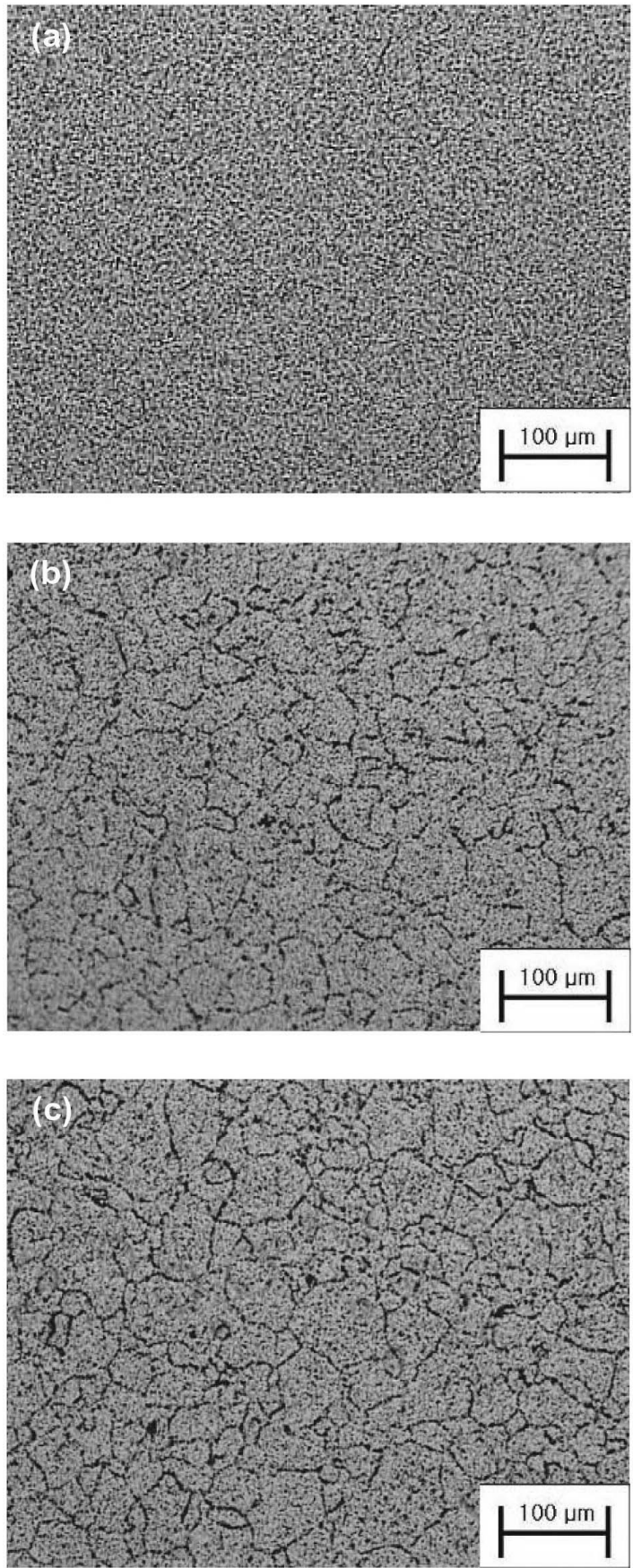
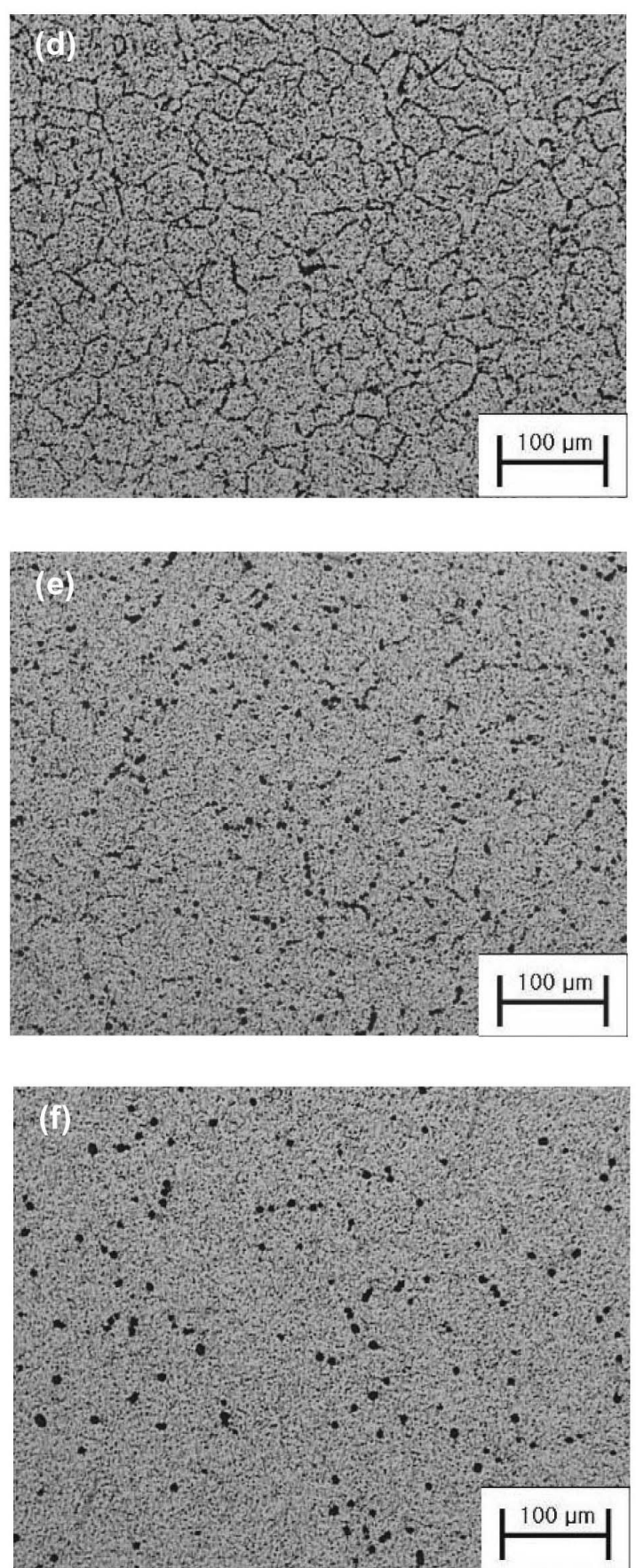

Fig. 3. Boron Distribution During Isothermal Holding at $900{ }^{\circ} \mathrm{C}$ after Quenching from $1200{ }^{\circ} \mathrm{C}$ : (a) $0 \mathrm{~s}$, (b) $20 \mathrm{~s}$, (c) $30 \mathrm{~s}$, (d) $60 \mathrm{~s}$, (e) $120 \mathrm{~s}$, and (f) $1000 \mathrm{~s}$. 
increases with an increasing holding time to $60 \mathrm{~s}$, and then when the holding time is longer than $60 \mathrm{~s}$, the segregation level decreases with an increasing the holding time.

From the above experimental results, it can be concluded that the critical time of the NGS of boron is between approximately 30 and $60 \mathrm{~s}$ in this sample.

\subsection{Comparison of NGS}

According to the behavior of the non-equilibrium segregation, solute boron atoms are transported to the grain boundaries by forming complexes with vacancies. The quenching-induced segregation [9] to prior austenite grain boundaries have been attributed to the diffusion of vacancy-solute complexes along the vacancy gradients to the grain boundary, which is the diffusion resulting from the supersaturated vacancies annihilated at the grain boundaries. If the holding time is sufficient, this nonequilibrium segregation formed by the diffusion of vacancy-solute complexes disappears and the level of segregation reaches full equilibrium. This means that the NGS phenomena occurs during a certain time and a time to reach the maximum level of non-equilibrium segregation exists. This is a very important concept in understanding the behavior of non-equilibrium segregation.

$\mathrm{Xu}$ and Song [10] proposed an isothermal kinetic model for NGS and suggested the concept of a critical time and a critical cooling rate for the non-equilibrium segregation. Based on these, the effective time concept predicting the level of non-equilibrium segregation during the cooling processes was also suggested by $\mathrm{Xu}$ and Song [10]. According to the effective time method, a certain effective time at a certain holding temperature can be calculated for any continuous cooling curve. Therefore, it is possible to calculate the effective time at a certain holding temperature corresponding to the continuous cooling from a higher temperature to a lower temperature. If the effective time during cooling calculated by the effective time method is equal to the critical time at the holding temperature, this cooling rate can be called the critical cooling rate. This is a basic concept of the effective time method [10] for non-equilibrium segregation. For most experiments and the general phenomena of the NGS, segregation always occurs during continuous cooling [5]. Therefore, it is very important to predict the NGS level for continuous cooling.

As mentioned above, the effective time method for the prediction of the non-equilibrium segregation level during continuous cooling was proposed by Xu and Song [10] in 1987. According to this method, any continuous cooling curve for a sample can be replaced by a corresponding stepped curve, each step of which was formed using horizontal and vertical segments in order to calculate an effective time at a certain temperature for this cooling sample. If the continuous cooling curve for a sample is replaced by the stepped curve consisting of $n$ steps, as shown in Fig. 4, the effective time corresponding to a certain temperature $T$ for each step in the stepped curve can be calculated and the effective time for the whole stepped curve corresponding to temperature $T$ can be given by $t_{e}$ :

$$
t_{e}(\mathbf{T})=\sum_{i=1}^{n} t_{i} \exp \left[-\frac{E_{A}\left(T-T_{i}\right)}{k T T_{i}}\right]
$$

where $E_{A}$ is the activation energy for the diffusion of complexes in the matrix. $t_{i}$ and $T_{i}$ are the isothermal holding time and temperature at the ith step of the stepped curve, respectively. As shown in Fig. 4, when the steps formed by horizontal and vertical segments are sufficiently small, the effective time of the stepped curve at a certain temperature will be practically equal to the effective time of the continuous cooling at the same temperature. Therefore, the effective time at a certain temperature $T$ for the continuous cooling curve can be calculated using the effective time formula as presented in Eq. (1). This means that the average diffusion distance of the diffusant during the cooling of the sample along the continuous cooling curve is the same as that of a sample at the holding temperature $T$ during the holding time, $t_{e}$. Therefore, it is possible that the segregation level of the solute atoms during continuous cooling can be converted into the segregation level of the solute atoms during the isothermal holding using the effective time method. In this way, the segregation level of boron during continuous cooling can be predicted easily from the distribution behavior of boron during the isothermal holding process.

The effective time during cooling was calculated using the Eq. (1). In the studied sample, the effective time of 1, 10,20 , and $40{ }^{\circ} \mathrm{C} / \mathrm{s}$ during the cooling from $1200{ }^{\circ} \mathrm{C}$ to $900^{\circ} \mathrm{C}$ is the same as $896,73,27$, and $4 \mathrm{~s}$ at the isothermal holding temperature of $900{ }^{\circ} \mathrm{C} . E_{A}=0.91 \mathrm{eV}$ [4] was used to calculate the effective time during the cooling.

From the above calculation results, it can be concluded that the cooling rate dependence of the grain boundary

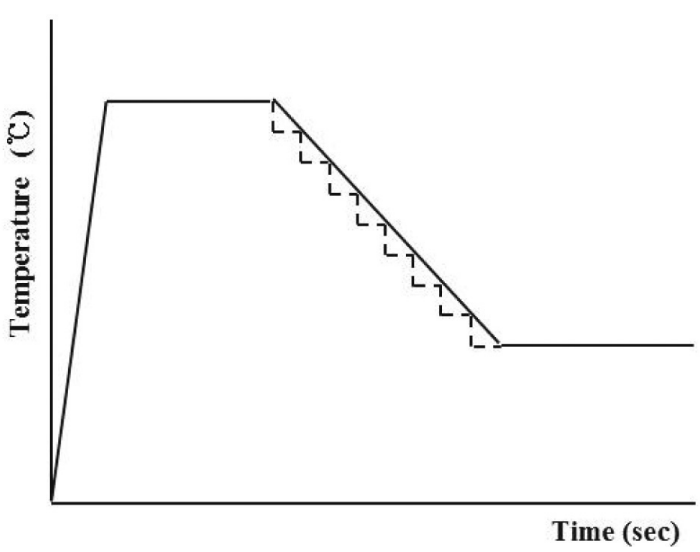

Fig. 4. Approximate Stepped Curve Corresponding to the Continuous Cooling Curve. 
segregation of boron coincides well with the time dependence of the grain boundary segregation of boron. That is, the cooling rate dependence of the NGS can be explained by its time dependence. This means that the level of the NGS of boron during cooling depends on the annihilation time of the supersaturated vacancy-boron complexes.

\section{CONCLUSIONS}

This article presents the results of an investigation of the boron distribution behavior in low carbon steel using a particle tracking autoradiography. The following conclusions are drawn.

- The non-equilibrium segregation of boron to the grain boundaries during cooling relies on the annihilation time of the supersaturated vacancy-boron complexes.

- The non-equilibrium grain boundary segregation of boron is strongly dependent on the cooling rate. The amount of segregation is highest at intermediate cooling rates $\left(10 \sim 20^{\circ} \mathrm{C} / \mathrm{s}\right)$.

- The cooling rate dependence of the grain boundary segregation of boron can be explained by the time dependence of the grain boundary segregation of boron in low carbon steel.

\section{ACKNOWLEDGMENTS}

This research was supported by the World Class University (WCU) program through the Korea Science and Engineering Foundation funded by the Ministry of Education, Science and Technology (Project No. R322008-000-10147-0).

\section{REFERENCES}

[ 1 ] M. Ueno and T. Inoue, Trans. Iron steel Inst. Jpn., Vol. 13, p.210, (1973).

[2] G. F. Melloy, P. R. Slimon and P. P. Podgursky, Metall. Trans., Vol. 4, p.2279, (1973).

[ 3 ] T. D. Xu, S. Song, Z. Yuan and Z. Yu, J. Mater. Sci., 25, p.1739, (1990).

[4] T. M. Williams, A. M. Stoneham and D. R. Harries, Met. Sci., Vol. 10, p.14, (1976).

[ 5 ] L. Karlsson, H. Norden and H. Odelius, Acta metall., Vol. 36, p.1-12, (1988).

[6] X. Hung, M. C. Chaurvedi, N. L. Richards and J. Jackman, Acta mater., Vol. 45, p. 3095-3107, (1997).

[7] S. Song, T. D. Xu and Z. Yuan, Acta metall., Vol. 37, p.319, (1989).

[ 8 ] R. G. Faulker, J. Mater. Sci., Vol. 16, p.373, (1981).

[9] X. L. He, Y. Y. Chu and J. J. Jonas, Acta metall., Vol. 37, p. 2905, (1989).

[10] T. D. Xu and S. Song, Acta metall., Vol. 37, p. 2499, (1989). 